\title{
New type of multivalued F-contraction involving fixed points on closed ball
}

\author{
Aftab Hussain ${ }^{\mathrm{a}, \mathrm{b}}$, Hafiz Farooq Ahmad ${ }^{\mathrm{c}, *}$, Muhammad Arshad ${ }^{\mathrm{b}}$, Muhammad Nazam ${ }^{\mathrm{b}}$ \\ ${ }^{a}$ Department of Mathematical Sciences, Lahore Leads University, Lahore - 54000, Pakistan. \\ ${ }^{b}$ Department of Mathematics, International Islamic University, H-10, Islamabad - 44000, Pakistan. \\ ${ }^{c}$ College of Computer Sciences and Information Technology (CCSIT) King Faisal University, Alahssa 31982, Kingdom of Saudi Arabia.
}

\begin{abstract}
This paper is a continuation of the investigations of F-contraction. The aim of this article is to extend the concept of Fcontraction on closed ball. We introduce the notion of Ćirić type multivalued F-contraction on closed ball and establish new fixed point theorems for Ćirić type multivalued F-contraction on closed ball in a complete metric space. Our results are very useful for the contraction of the mapping only on closed ball instead on the whole space. Some comparative examples are constructed whose illustrate the superiority of our results. Our results provide extension as well as substantial generalizations and improvements of several well-known results in the existing comparable literature. (C)2017 All rights reserved.
\end{abstract}

Keywords: Metric space, fixed point, F-contraction, closed ball.

2010 MSC: 46S40, 47H10, 54H25.

\section{Introduction}

We recollect some essential notations, required definitions, and primary results coherent with the literature. For a nonempty set $X$, we denote by $N(X)$ the class of all nonempty subsets of $X$. Let $(X, d)$ be a metric space. For $x \in X$ and $A \subseteq X$, we denote $D(x, A)=\inf \{d(x, y): y \in A\}$. We denote by $C L(X)$ the class of all nonempty closed subsets of $X$, by $\mathrm{CB}(\mathrm{X})$ the class of all nonempty closed and bounded subsets of $X$ and by $K(X)$ the class of all compact subsets of $X$. Let $H$ be the Hausdorff metric induced by the metric $d$ on $X$, that is,

$$
H(A, B)=\max \left\{\sup _{x \in A} D(x, B), \sup _{y \in B} D(y, A)\right\},
$$

for every $A, B \in C B(X)$. Let $T: X \longrightarrow C B(X)$ be a multi-valued mapping. A point $q \in X$ is said to be a fixed point of $T$ if $q \in T q$.

The fixed point theory of multivalued contraction mappings using the Hausdorff metric was initiated by Nadler [35], who extended the Banach contraction principle to multivalued mappings.

\footnotetext{
${ }^{*}$ Corresponding author

Email addresses: aftabshh@gmail.com (Aftab Hussain), farooq.ahmad@seecs.edu.pk (Hafiz Farooq Ahmad), marshadzia@iiu.edu.pk (Muhammad Arshad), nazim.phdma47@iiu.edu.pk (Muhammad Nazam)

doi:10.22436/jmcs.017.02.06
} 
Theorem 1.1 ([35]). Let $(\mathrm{X}, \mathrm{d})$ be a complete metric space and $\mathrm{T}: \mathrm{X} \longrightarrow \mathrm{CB}(\mathrm{X})$ be a multi-valued mapping such that for all $x, y \in X$

$$
H(T x, T y) \leqslant k d(x, y),
$$

where $0<\mathrm{k}<1$. Then $\mathrm{T}$ has a fixed point.

From the application point of view the situation is not yet completely satisfactory because there are many situations in which the mappings are not contractive on the whole space but instead they are contractive on its subsets. However, by imposing a subtle restriction, one can establish the existence of a fixed point of such mappings. Shoaib et al. [41] proved significant results concerning the existence of fixed points of the dominated self-mappings satisfying some contractive conditions on closed ball in a 0-complete quasi-partial metric space. Other results on closed ball can be seen in [9-12]. Over the years, fixed point theory has been generalized in different ways by several mathematicians (see $[2,3,8,13-$ 19, 23-25, 29, 31, 33, 40].

For $x \in X$ and $\varepsilon>0, \overline{B(x, \varepsilon)}=\{y \in X: d(x, y) \leqslant \varepsilon\}$ is a closed ball in $(X, d)$.

Definition 1.2 ([38]). Let $T: X \rightarrow X$ and $\alpha: X \times X \rightarrow[0,+\infty)$. We say that $T$ is $\alpha$-admissible if $x, y \in X$, $\alpha(x, y) \geqslant 1$ implies that $\alpha(T x, T y) \geqslant 1$.

Definition 1.3 ([37]). Let $T: X \rightarrow X$ and $\alpha, \eta: X \times X \rightarrow[0,+\infty)$ be two functions. We say that $T$ is $\alpha$-admissible mapping with respect to $\eta$ if $x, y \in X, \alpha(x, y) \geqslant \eta(x, y)$ implies that $\alpha(T x, T y) \geqslant \eta(T x, T y)$.

If $\eta(x, y)=1$, then above definition reduces to Definition 1.2. If $\alpha(x, y)=1$, then $T$ is called an $\eta$-subadmissible mapping.

Definition 1.4 ([26]). Let $(X, d)$ be a metric space. Let $T: X \rightarrow X$ and $\alpha, \eta: X \times X \rightarrow[0,+\infty)$ be two functions. We say that $T$ is $\alpha-\eta$-continuous mapping on $(X, d)$ if for given $x \in X$, and sequence $\left\{x_{n}\right\}$ with

$$
x_{n} \rightarrow x \text { as } n \rightarrow \infty, \alpha\left(x_{n}, x_{n+1}\right) \geqslant \eta\left(x_{n}, x_{n+1}\right) \text { for all } n \in \mathbb{N} \Rightarrow T x_{n} \rightarrow T x .
$$

Hussain et al. [27] modified the notions of $\alpha_{*}$-admissible and $\alpha_{*}-\psi$-contractive mappings as follows:

Definition 1.5 ([27]). Let $T: X \rightarrow 2^{X}$ be a multifunction, $\alpha, \eta: X \times X \rightarrow[0,+\infty)$ be two functions where $\eta$ is bounded. We say that $T$ is $\alpha_{*}$-admissible mapping with respect to $\eta$ if $\alpha(x, y) \geqslant \eta(x, y)$ implies $\alpha_{*}(T x, T y) \geqslant \eta_{*}(T x, T y), x, y \in X$, where $\alpha_{*}(A, B)=\inf \{\alpha(x, y): x \in A, y \in B\}$ and $\eta_{*}(A, B)=$ $\sup \{\eta(x, y): x \in A, y \in B\}$.

If $\eta(x, y)=1$ for all $x, y \in X$, then this definition reduces to [27, Definition 4.1]. In Definition 1.5, if $\alpha(x, y)=1$ for all $x, y \in X$, then $T$ is called $\eta_{*}$-subadmissible mapping.

Definition 1.6 ([33]). Let $(X, d)$ be a metric space. Let $T: X \rightarrow \operatorname{CL}(X)$ and $\alpha: X \times X \rightarrow[0,+\infty)$ be two functions. We say that $T$ is $\alpha$-continuous multivalued mapping on $(C L(X), H)$ if for given $x \in X$, and sequence $\left\{x_{n}\right\}$ with $\lim _{n \rightarrow \infty} d\left(x_{n}, x\right)=0, \alpha\left(x_{n}, x_{n+1}\right) \geqslant 1$ for all $n \in \mathbb{N}$ we have $\lim _{n \rightarrow \infty} H\left(T x_{n}, T x\right)=0$.

In 2012, Wardowski [45] introduced a new type of contractions called F-contraction and proved new fixed point theorems concerning F-contraction. He generalized the Banach contraction principle in a different way than as it was done by different investigators; see [1, 4, 6, 7, 20-22, 28, 32, 34, 39, 40, 42-44]. Piri et al. [36] defined the F-contraction as follows.

Definition $1.7([36])$. Let $(X, d)$ be a metric space. A mapping $T: X \rightarrow X$ is said to be an F-contraction if there exists $\tau>0$ such that

$$
\forall x, y \in X, d(T x, T y)>0 \Rightarrow \tau+F(d(T x, T y)) \leqslant F(d(x, y))
$$

where $F: \mathbb{R}_{+} \rightarrow \mathbb{R}$ is a mapping satisfying the following conditions: 
(F1) $F$ is strictly increasing, i.e., for all $x, y \in \mathbb{R}_{+}$such that $x<y, F(x)<F(y)$;

(F2) for each sequence $\left\{\alpha_{n}\right\}_{n=1}^{\infty}$ of positive numbers, $\lim _{n \rightarrow \infty} \alpha_{n}=0$ if and only if $\lim _{n \rightarrow \infty} F\left(\alpha_{n}\right)=-\infty$;

(F3) there exists $k \in(0,1)$ such that $\lim _{\alpha \rightarrow 0^{+}} \alpha^{k} F(\alpha)=0$.

We denote by $\Delta_{\mathrm{F}}$, the set of all functions satisfying the conditions (F1)-(F3).

Example 1.8 ([45]). Let $F: \mathbb{R}_{+} \rightarrow \mathbb{R}$ be given by the formula $F(\alpha)=\ln \alpha$. It is clear that $F$ satisfies (F1)-(F3) for any $\mathrm{k} \in(0,1)$. Each mapping $T: X \rightarrow X$ satisfying (1.1) is an F-contraction such that

$$
d(T x, T y) \leqslant e^{-\tau} d(x, y) \text { for all } x, y \in X, T x \neq T y .
$$

It is clear that for $x, y \in X$ such that $T x=T y$ the inequality $d(T x, T y) \leqslant e^{-\tau} d(x, y)$, also holds, i.e., $T$ is a Banach contraction.

Example 1.9 ([45]). If $F(\alpha)=\ln \alpha+\alpha, \alpha>0$, then $F$ satisfies (F1)-(F3) and the condition (1.1) is of the form

$$
\frac{d(T x, T y)}{d(x, y)} \leqslant e^{d(T x, T y)-d(x, y)} \leqslant e^{-\tau} \text { for all } x, y \in X, T x \neq T y
$$

Remark 1.10. From (F1) and (1.1) it is easy to conclude that every F-contraction is necessarily continuous.

Wardowski [45] stated a modified version of the Banach contraction principle as follows.

Theorem 1.11 ([45]). Let $(\mathrm{X}, \mathrm{d})$ be a complete metric space and let $\mathrm{T}: \mathrm{X} \rightarrow \mathrm{X}$ be an $\mathrm{F}$-contraction. Then $\mathrm{T}$ has a unique fixed point $x^{*} \in X$ and for every $x \in X$ the sequence $\left\{T^{n} \chi\right\}_{\mathfrak{n} \in \mathbb{N}}$ converges to $x^{*}$.

Hussain et al. [26] introduced the following family of new functions.

Let $\Delta_{G}$ denote the set of all functions $G:\left(\mathbb{R}^{+}\right)^{4} \rightarrow \mathbb{R}^{+}$satisfying: (G) for all $t_{1}, t_{2}, t_{3}, t_{4} \in \mathbb{R}^{+}$with $t_{1} t_{2} t_{3} t_{4}=0$, there exists $\tau>0$ such that $G\left(t_{1}, t_{2}, t_{3}, t_{4}\right)=\tau$.

Definition 1.12 ([26]). Let $(X, d)$ be a metric space and $T$ be a self-mapping on $X$. Let $\alpha, \eta: X \times X \rightarrow$ $[0,+\infty)$ be two functions. We say that $T$ is $\alpha-\eta-G F-$ contraction if for $x, y \in X$, with $\eta(x, T x) \leqslant \alpha(x, y)$ and $\mathrm{d}(\mathrm{T} x, \mathrm{Ty})>0$ we have

$$
G(d(x, T x), d(y, T y), d(x, T y), d(y, T x))+F(d(T x, T y)) \leqslant F(d(x, y)),
$$

where $\mathrm{G} \in \Delta_{\mathrm{G}}$ and $\mathrm{F} \in \Delta_{\mathrm{F}}$.

Lately, Acar et al. [5] introduced the concept of generalized multivalued F-contraction mappings and established a fixed point result, which was a proper generalization of some multivalued fixed point theorems including Nadler's.

Definition $1.13([5])$. Let $(X, d)$ be a metric space and $T: X \longrightarrow C B(X)$ be a mapping. Then $T$ is said to be a generalized multivalued F-contraction if $\mathrm{F} \in \Delta_{\mathrm{F}}$ and there exists $\tau>0$ such that

$$
x, y \in X, H(T x, T y)>0 \Rightarrow \tau+F(H(T x, T y)) \leqslant F(M(x, y)),
$$

where

$$
M(x, y)=\max \left\{d(x, y), D(x, T x), D(y, T y), \frac{1}{2}[D(x, T y)+D(y, T x)]\right\} .
$$

Theorem 1.14 ([5]). Let $(\mathrm{X}, \mathrm{d})$ be a complete metric space and $\mathrm{T}: \mathrm{X} \rightarrow \mathrm{K}(\mathrm{X})$ be a generalized multivalued $\mathrm{F}$-contraction. If $\mathrm{T}$ or $\mathrm{F}$ is continuous, then $\mathrm{T}$ has a fixed point in $\mathrm{X}$.

We now introduce the concept of $\alpha-\eta$-continuous for multivalued mappings in metric spaces.

Definition 1.15. Let $(X, d)$ be a metric space. Let $T: X \rightarrow C B(X)$ and $\alpha, \eta: X \times X \rightarrow[0,+\infty)$ be two functions. We say that $T$ is $\alpha$ - $\eta$-continuous multivalued mapping on $(\mathrm{CB}(X), H)$ if for given $x \in X$, and 
sequence $\left\{x_{n}\right\}$ with $x_{n} \stackrel{d}{\rightarrow} x$ as $n \rightarrow \infty, \alpha\left(x_{n}, x_{n+1}\right) \geqslant \eta\left(x_{n}, x_{n+1}\right)$ for all $n \in \mathbb{N}$ we have $T x_{n} \stackrel{H}{\rightarrow} T x$, that is $\lim _{n \rightarrow \infty} d\left(x_{n}, x\right)=0$ and $\alpha\left(x_{n}, x_{n+1}\right) \geqslant \eta\left(x_{n}, x_{n+1}\right)$ for all $n \in \mathbb{N}$ we have $\lim _{n \rightarrow \infty} H\left(T x_{n}, T x\right)=0$.

The following result regarding the existence of the fixed point of the mapping satisfying a contractive condition on the closed ball is given in [30, Theorem 5.1.4]. The result is very useful in the sense that it requires the contraction of the mapping only on the closed ball instead on the whole space.

Theorem 1.16 ([30]). Let $(X, d)$ be a complete metric space, $\mathrm{T}: \mathrm{X} \rightarrow \mathrm{X}$ be a mapping, $\mathrm{r}>0$, and $\mathrm{x}_{0}$ be an arbitrary point in $\mathrm{X}$. Suppose there exists $\mathrm{k} \in[0,1)$ with

$$
\mathrm{d}(\mathrm{T} x, \mathrm{Ty}) \leqslant \mathrm{kd}(\mathrm{x}, \mathrm{y}) \text { for all } x, y \in \mathrm{Y}=\overline{\mathrm{B}\left(\mathrm{x}_{0}, \mathrm{r}\right)}
$$

and $\mathrm{d}\left(\mathrm{x}_{0}, \mathrm{~T} \mathrm{x}_{0}\right)<(1-\mathrm{k}) \mathrm{r}$. Then there exists a unique point $\mathrm{x}^{*}$ in $\overline{\mathrm{B}\left(\mathrm{x}_{0}, \mathrm{r}\right)}$ such that $\mathrm{x}^{*}=\mathrm{S} \mathrm{x}^{*}$.

\section{Fixed point theorem for Ćirić type GF-contraction on closed ball}

In this section, we introduce multivalued fixed point theorem for modified F-contraction on closed

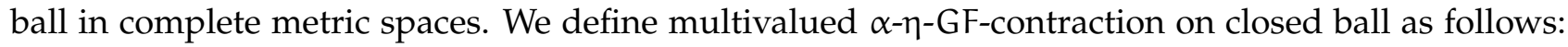

Definition 2.1. Let $(X, d)$ be a metric space and $T: X \rightarrow C B(X)$. Also suppose that $\alpha, \eta: X \times X \rightarrow$

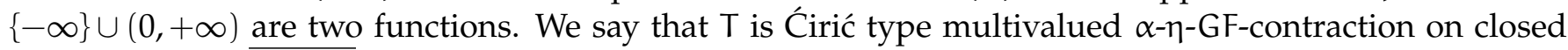
ball if for $x, y \in \overline{\mathrm{B}\left(\mathrm{x}_{0}, \mathrm{r}\right)} \subseteq \mathrm{X}$ with $\eta_{*}(x, T x) \leqslant \alpha_{*}(x, y)$ and $\mathrm{T} x \neq \mathrm{Ty}$ we have

$$
2 G(D(x, T x), D(y, T y), D(x, T y), D(y, T x))+F(H(T x, T y)) \leqslant F(M(x, y)),
$$

where

$$
M(x, y)=\max \left\{d(x, y), D(x, T x), D(y, T y), \frac{1}{2}[D(x, T y)+D(y, T x)]\right\}
$$

and

$$
\mathrm{D}\left(\mathrm{x}_{0}, \mathrm{~T} x_{0}\right) \leqslant(1-\mathrm{k}) \mathrm{r}
$$

where $k \in[0,1), G \in \Delta_{G}$, and $F \in \Delta_{F}$.

Now we state our main result.

Theorem 2.2. Let $(\mathrm{X}, \mathrm{d})$ be a complete metric space. Suppose $\mathrm{T}: \mathrm{X} \rightarrow \mathrm{CB}(\mathrm{X})$ is Ćirić type multivalued $\alpha-\eta-\mathrm{GF}-$ contraction on closed ball $\overline{\mathrm{B}\left(\mathrm{x}_{0}, \mathrm{r}\right)}$ satisfying the following assertions:

(i) $\mathrm{T}$ is an $\alpha_{*}$-admissible mapping with respect to $\eta$;

(ii) there exists $x_{0} \in X$ such that $\alpha_{*}\left(x_{0}, T x_{0}\right) \geqslant \eta_{*}\left(x_{0}, T x_{0}\right)$;

(iii) $\sum_{j=0}^{\mathbb{N}} \mathrm{D}\left(\mathrm{x}_{0}, T x_{0}\right) \leqslant r$ for all $j \in \mathbb{N}$;

(iv) $\mathrm{T}$ is $\alpha$ - $\eta$-continuous multivalued mapping.

Then there exists a fixed point $x^{*}$ in $\overline{\mathrm{B}\left(\mathrm{x}_{0}, \mathrm{r}\right)}$ such that $x^{*} \in \mathrm{T} x^{*}$.

Proof. Let $x_{0} \in X$, such that $\alpha_{*}\left(x_{0}, T x_{0}\right) \geqslant \eta_{*}\left(x_{0}, T x_{0}\right)$. Since $T$ is an $\alpha_{*}$-admissible mapping with respect to $\eta$ then there exists $x_{1} \in T x_{0}$ such that

$$
\alpha\left(x_{0}, x_{1}\right)=\alpha_{*}\left(x_{0}, T x_{0}\right) \geqslant \eta_{*}\left(x_{0}, T x_{0}\right)=\eta\left(x_{0}, x_{1}\right) .
$$

If $x_{1} \in T x_{1}$, then $x_{1}$ is a fixed point of $T$. So, we assume that $x_{0} \neq x_{1}$, then $T x_{0} \neq T x_{1}$. Since $F$ is continuous from the right, there exists a real number $h>1$ such that

$$
F\left(h H\left(T x_{0}, T x_{1}\right)\right)<F\left(H\left(T x_{0}, T x_{1}\right)\right)+G\left(D\left(x_{0}, T x_{0}\right), D\left(x_{1}, T x_{1}\right), D\left(x_{0}, T x_{1}\right), D\left(x_{1}, T x_{0}\right)\right) .
$$


Now from $\mathrm{D}\left(\mathrm{x}_{1}, \mathrm{~T} x_{1}\right)<\mathrm{hH}\left(T x_{0}, T x_{1}\right)$, we deduce that there exists $x_{2} \in \mathrm{T} x_{1}$ such that $d\left(x_{1}, x_{2}\right) \leqslant$ $h H\left(T x_{0}, T x_{1}\right)$. Consequently, we obtain

$$
\mathrm{F}\left(\mathrm{D}\left(\mathrm{x}_{1}, \mathrm{~T} x_{1}\right)\right) \leqslant \mathrm{F}\left(\mathrm{hH}\left(\mathrm{T} x_{0}, \mathrm{~T} x_{1}\right)\right)<\mathrm{F}\left(\mathrm{H}\left(\mathrm{T} x_{0}, T x_{1}\right)\right)+\mathrm{G}\left(\mathrm{D}\left(\mathrm{x}_{0}, \mathrm{~T} x_{0}\right), \mathrm{D}\left(\mathrm{x}_{1}, \mathrm{~T} x_{1}\right), \mathrm{D}\left(\mathrm{x}_{0}, T x_{1}\right), \mathrm{D}\left(\mathrm{x}_{1}, \mathrm{~T} x_{0}\right)\right),
$$

which implies

$$
\begin{aligned}
2 G\left(D\left(x_{0}, T x_{0}\right), D\left(x_{1}, T x_{1}\right), D\left(x_{0}, T x_{1}\right), D\left(x_{1}, T x_{0}\right)\right)+F\left(D\left(x_{1}, x_{2}\right)\right) \\
\leqslant \\
\quad 2 G\left(D\left(x_{0}, T x_{0}\right), D\left(x_{1}, T x_{1}\right), D\left(x_{0}, T x_{1}\right), D\left(x_{1}, T x_{0}\right)\right)+F\left(H\left(T x_{0}, T x_{1}\right)\right) \\
\quad+G\left(D\left(x_{0}, T x_{0}\right), D\left(x_{1}, T x_{1}\right), D\left(x_{0}, T x_{1}\right), D\left(x_{1}, T x_{0}\right)\right) \\
\leqslant F\left(M\left(x_{0}, x_{1}\right)\right)+G\left(D\left(x_{0}, T x_{0}\right), D\left(x_{1}, T x_{1}\right), D\left(x_{0}, T x_{1}\right), D\left(x_{1}, T x_{0}\right)\right),
\end{aligned}
$$

and hence

$$
\begin{aligned}
& \mathrm{G}\left(\mathrm{D}\left(\mathrm{x}_{0}, T x_{0}\right), \mathrm{D}\left(\mathrm{x}_{1}, T x_{1}\right), \mathrm{D}\left(\mathrm{x}_{0}, T x_{1}\right), 0\right)+\mathrm{F}\left(\mathrm{M}\left(\mathrm{T} x_{0}, T x_{1}\right)\right) \\
& \quad \leqslant \mathrm{F}\left(\max \left\{\mathrm{d}\left(\mathrm{x}_{0}, \mathrm{x}_{1}\right), \mathrm{D}\left(\mathrm{x}_{0}, T x_{0}\right), \mathrm{D}\left(\mathrm{x}_{1}, T x_{1}\right), \frac{\mathrm{D}\left(\mathrm{x}_{0}, T x_{1}\right)+\mathrm{D}\left(\mathrm{x}_{1}, T x_{0}\right)}{2}\right\}\right) .
\end{aligned}
$$

Now, since $d\left(x_{0}, x_{1}\right) \cdot d\left(x_{1}, x_{2}\right) \cdot d\left(x_{0}, x_{2}\right) \cdot 0=0$, so from $(G)$ there exists $\tau>0$ such that

$$
\mathrm{G}\left(\mathrm{D}\left(\mathrm{x}_{0}, T \mathrm{x}_{0}\right), \mathrm{D}\left(\mathrm{x}_{1}, \mathrm{~T} \mathrm{x}_{1}\right), \mathrm{D}\left(\mathrm{x}_{0}, \mathrm{~T} \mathrm{x}_{1}\right), 0\right)=\tau \text {. }
$$

Therefore from (2.1) we deduce that

$$
\begin{aligned}
\tau+F\left(d\left(x_{1}, T x_{1}\right)\right) & \leqslant F\left(\max \left\{d\left(x_{0}, x_{1}\right), D\left(x_{0}, T x_{0}\right), D\left(x_{1}, T x_{1}\right), \frac{D\left(x_{0}, T x_{1}\right)+D\left(x_{1}, T x_{0}\right)}{2}\right\}\right) \\
& =F\left(\max \left\{d\left(x_{0}, x_{1}\right), D\left(x_{0}, T x_{0}\right), D\left(x_{1}, T x_{1}\right), \frac{D\left(x_{0}, T x_{1}\right)+D\left(x_{1}, T x_{0}\right)}{2}\right\}\right)-\tau \\
& =F\left(\max \left\{d\left(x_{0}, x_{1}\right), D\left(x_{0}, T x_{0}\right), D\left(x_{1}, T x_{1}\right), \frac{D\left(x_{0}, x_{2}\right)+D\left(x_{1}, x_{1}\right)}{2}\right\}\right)-\tau \\
& \leqslant F\left(\max \left\{D\left(x_{0}, T x_{0}\right), D\left(x_{1}, T x_{1}\right)\right\}\right)-\tau .
\end{aligned}
$$

If $\max \left\{\mathrm{D}\left(\mathrm{x}_{0}, \mathrm{~T} x_{0}\right), \mathrm{D}\left(\mathrm{x}_{1}, \mathrm{~T} x_{1}\right)\right\}=\mathrm{D}\left(\mathrm{x}_{1}, \mathrm{~T} x_{1}\right)$, then (2.2) becomes

$$
F\left(D\left(x_{1}, T x_{1}\right)\right) \leqslant F\left(D\left(x_{1}, T x_{1}\right)\right)-\tau,
$$

which does not hold true. Thus $\max \left\{\mathrm{D}\left(\mathrm{x}_{0}, \mathrm{~T} x_{0}\right), \mathrm{D}\left(\mathrm{x}_{1}, \mathrm{~T} x_{1}\right)\right\}=\mathrm{D}\left(\mathrm{x}_{0}, \mathrm{~T} x_{0}\right)$. Consequently,

$$
F\left(D\left(x_{1}, T x_{1}\right)\right) \leqslant F\left(D\left(x_{0}, T x_{0}\right)\right)-\tau .
$$

From (iii), we deduce that

$$
d\left(x_{0}, x_{1}\right)=D\left(x_{0}, T x_{0}\right) \leqslant r,
$$

thus, $x_{1} \in \overline{\mathrm{B}\left(\mathrm{x}_{0}, r\right)}$. Suppose $x_{2} \ldots . x_{j} \in \overline{\mathrm{B}\left(x_{0}, r\right)}$ for some $j \in \mathbb{N}$. As $F$ is strictly increasing and repeating these steps for $x_{2} \ldots . x_{j}$, we obtain

$$
\mathrm{D}\left(\mathrm{x}_{\mathfrak{j}}, T x_{j}\right) \leqslant \mathrm{D}\left(\mathrm{x}_{j-1}, T x_{j-1}\right) .
$$

Now, using triangular inequality and (2.3), we get

$$
d\left(x_{0}, x_{j+1}\right) \leqslant d\left(x_{0}, x_{1}\right)+\ldots+d\left(x_{j}, x_{j+1}\right) \leqslant \sum_{j=0}^{\mathbb{N}} D\left(x_{0}, T x_{0}\right) \leqslant r .
$$

Thus $x_{j+1} \in \overline{\mathrm{B}\left(x_{0}, r\right)}$. Hence $x_{n} \in \overline{\mathrm{B}\left(x_{0}, r\right)}$ for all $n \in N$. By continuing this process, we obtain a sequence $\left\{x_{n}\right\} \subset X$ such that $x_{n} \notin T x_{n}, x_{n+1} \in T x_{n}$,

$$
\eta\left(x_{n-1}, x_{n}\right)=\eta_{*}\left(x_{n-1}, T x_{n-1}\right) \leqslant \alpha_{*}\left(x_{n-1}, T x_{n-1}\right)=\alpha\left(x_{n-1}, x_{n}\right),
$$

and 


$$
\begin{aligned}
\tau+ & F\left(d\left(x_{n}, x_{n+1}\right)\right) \\
& \leqslant F\left(\max \left\{d\left(x_{n-1}, x_{n}\right), D\left(x_{n-1}, T x_{n-1}\right), D\left(x_{n}, T x_{n}\right), \frac{D\left(x_{n-1}, T x_{n}\right)+D\left(x_{n}, T x_{n-1}\right)}{2}\right\}\right) \\
& =F\left(\max \left\{d\left(x_{n-1}, x_{n}\right), D\left(x_{n-1}, T x_{n-1}\right), D\left(x_{n}, T x_{n}\right), \frac{D\left(x_{n-1}, T x_{n}\right)}{2}\right\}\right)-\tau \\
& \leqslant F\left(\max \left\{D\left(x_{n-1}, T x_{n-1}\right), D\left(x_{n}, T x_{n}\right)\right\}\right)-\tau .
\end{aligned}
$$

If $\max \left\{\mathrm{D}\left(x_{n-1}, T x_{n-1}\right), D\left(x_{n}, T x_{n}\right)\right\}=D\left(x_{n}, T x_{n}\right)$, then

$$
F\left(D\left(x_{n}, T x_{n}\right)\right) \leqslant F\left(D\left(x_{n}, T x_{n}\right)\right)-\tau .
$$

Thus, $\max \left\{\mathrm{D}\left(\mathrm{x}_{\mathrm{n}-1}, \mathrm{~T} x_{\mathrm{n}-1}\right), \mathrm{D}\left(\mathrm{x}_{\mathrm{n}}, \mathrm{T} x_{\mathrm{n}}\right)\right\}=\mathrm{D}\left(\mathrm{x}_{\mathrm{n}-1}, \mathrm{~T} x_{\mathrm{n}-1}\right)$, we obtain

$$
F\left(d\left(x_{n}, x_{n+1}\right)\right) \leqslant F\left(D\left(x_{n-1}, T x_{n-1}\right)\right)-\tau,
$$

for all $n \in \mathbb{N} \cup\{0\}$. By (2.4), we have

$$
F\left(d\left(x_{n}, x_{n+1}\right)\right) \leqslant F\left(D\left(x_{n-1}, T x_{n-1}\right)\right)-\tau \leqslant F\left(D\left(x_{n-2}, T x_{n-2}\right)\right)-2 \tau \leqslant \cdots \leqslant F\left(D\left(x_{0}, T x_{0}\right)\right)-n \tau,
$$

for all $n \in \mathbb{N}$. Since $F \in \Delta_{F}$, so by taking limit as $n \longrightarrow \infty$ in (2.5), we deduce

$$
\lim _{n \rightarrow \infty} F\left(d\left(x_{n}, x_{n+1}\right)\right)=-\infty \Longleftrightarrow \lim _{n \rightarrow \infty} d\left(x_{n}, x_{n+1}\right)=0 .
$$

Now from (F3), there exists $0<k<1$ such that

$$
\lim _{n \rightarrow \infty}\left[d\left(x_{n}, x_{n+1}\right)\right]^{k} F\left(d\left(x_{n}, x_{n+1}\right)\right)=0 .
$$

By (2.4), we have

$$
\begin{aligned}
& d\left(x_{n}, x_{n+1}\right)^{k} F\left(d\left(x_{n}, x_{n+1}\right)\right)-d\left(x_{n}, x_{n+1}\right)^{k} F\left(d\left(x_{0}, x_{1}\right)\right) \\
& \quad \leqslant d\left(x_{n}, x_{n+1}\right)^{k}\left[F\left(d\left(x_{0}, x_{1}\right)-n \tau\right)\right]-d\left(x_{n}, x_{n+1}\right)^{k} F\left(d\left(x_{0}, x_{1}\right)\right) \\
& \quad=-n \tau\left[d\left(x_{n}, x_{n+1}\right)\right]^{k} \leqslant 0 .
\end{aligned}
$$

Letting $\mathrm{n} \longrightarrow \infty$ in (2.8) and applying (2.6) and (2.7), we have,

$$
\lim _{n \rightarrow \infty} n\left[d\left(x_{n}, x_{n+1}\right)\right]^{k}=0,
$$

we observe that from (2.9), then there exists $n_{1} \in \mathbb{N}$, such that $n\left(d\left(x_{n}, x_{n+1}\right)\right)^{k} \leqslant 1$ for all $n \geqslant n_{1}$, we get

$$
d\left(x_{n}, x_{n+1}\right) \leqslant \frac{1}{n^{\frac{1}{k}}} \text { for all } n \geqslant n_{1} .
$$

Now, $m, n \in \mathbb{N}$ such that $m>n \geqslant n_{1}$. Then, by the triangle inequality and from (2.10) we have

$$
\begin{aligned}
d\left(x_{n}, x_{m}\right) & \leqslant d\left(x_{n}, x_{n+1}\right)+d\left(x_{n+1}, x_{n+2}\right)+d\left(x_{n+2}, x_{n+3}\right)+\cdots+d\left(x_{m-1}, x_{m}\right) \\
& =\sum_{i=n}^{m-1} d\left(x_{i}, x_{i+1}\right) \leqslant \sum_{i=n}^{\infty} d\left(x_{i}, x_{i+1}\right) \leqslant \sum_{i=n}^{\infty} \frac{1}{i^{\frac{1}{k}}} .
\end{aligned}
$$

The series $\sum_{i=n}^{\infty} \frac{1}{i \frac{1}{k}}$ is convergent. This implies that $\left\{x_{n}\right\}$ is a Cauchy sequence. Since $X$ is a complete metric space, there exists $x^{*} \in X$ such that $\lim _{n \rightarrow \infty} d\left(x_{n}, x^{*}\right)=0$. By (2.3) and $\alpha-\eta$-continuity of the multivalued mapping $\mathrm{T}$, we get

$$
\lim _{n \rightarrow \infty} H\left(T x_{n}, T x^{*}\right)=0 \text {. }
$$

Now we obtain

$$
\mathrm{D}\left(x^{*}, T x^{*}\right)=\lim _{n \rightarrow \infty} \mathrm{D}\left(x_{n+1}, T x^{*}\right) \leqslant \lim _{n \rightarrow \infty} \mathrm{H}\left(T x_{n}, T x^{*}\right)=0 .
$$

Therefore, $x^{*} \in T x^{*}$ and hence $T$ has a fixed point. 
Example 2.3. Let $X=\mathbb{R}^{+}$. Define $T: X \rightarrow C B(X), \alpha: X \times X \rightarrow\{-\infty\} \cup(0,+\infty), \eta: X \times X \rightarrow \mathbb{R}^{+}$, $\mathrm{G}:\left(\mathbb{R}^{+}\right)^{4} \rightarrow \mathbb{R}^{+}$, and $\mathrm{F}: \mathbb{R}^{+} \rightarrow \mathbb{R}$ by

$$
\begin{array}{rlrl}
\mathrm{T} x & = \begin{cases}{\left[0, \frac{x}{3}\right],} & \text { if } x \in[0,1], \\
2 x, & \text { if } x \in(1, \infty),\end{cases} & \alpha(x, y)= \begin{cases}e^{x+y}, & \text { if } x \in[0,1], \\
\frac{1}{3}, & \text { otherwise, }\end{cases} \\
\eta(x, y) & =\frac{1}{2} \text { for all } x, y \in X, & G\left(t_{1}, t_{2}, t_{3}, t_{4}\right) & =\tau>0 \text { and } F(t)=\ln t \text { with } t>0 .
\end{array}
$$

And $x_{0}=\frac{1}{2}, r=1, \overline{B\left(x_{0}, r\right)}=[0,1]$, then

$$
\mathrm{d}\left(\frac{1}{2}, \mathrm{~T} \frac{1}{2}\right)=\left|\frac{1}{2}-\frac{1}{6}\right|=\frac{1}{3}<\mathrm{r} .
$$

If $x, y \in \overline{\mathrm{B}\left(x_{0}, r\right)}$, then $\alpha(x, y)=e^{x+y} \geqslant \frac{1}{2}=\eta(x, y)$. On the other hand, $T x \in[0,1]$ for all $x \in[0,1]$. Then $\alpha(T x, T y) \geqslant \eta(x, T x)$ with $H(T x, T y)=\left|\frac{x}{3}-\frac{y}{3}\right|>0$ and clearly $\alpha(0, T 0) \geqslant \eta(0, T 0)$. Hence we have

$$
H(T x, T y)=\left|\frac{x}{3}-\frac{y}{3}\right|<|x-y| \leqslant M(x, y) .
$$

Consequently,

$$
\tau+F(H(T x, T y))=\tau+\ln H(T x, T y) \leqslant \ln M(x, y)=F(M(x, y)) .
$$

If $x \notin \overline{\mathrm{B}\left(x_{0}, r\right)}$ or $y \notin \overline{\mathrm{B}\left(x_{0}, r\right)}$, then $\alpha(x, y)=\frac{1}{3} \ngtr \frac{1}{2}=\eta(x, y)$, either

$$
\begin{aligned}
2|x-y| & >|x-y|, \\
|2 x-2 y| & >|x-y|, \\
|T x-T y| & >|x-y|, \\
\tau+F(d(T x, T y)) & \geqslant F(d(x, y)) .
\end{aligned}
$$

Then the contractive condition does not hold on X.

\section{Conclusion}

In this connection, the main aim of our paper is to present fixed point theorem for modified Fcontraction on closed ball for multivalued mapping and different from F-contractions given in [26, 36, 45]. Existence of fixed point results of such type of F-contraction on closed ball in complete metric space are established. The study of results is very useful in the sense that it requires the F-contraction mapping only on the closed ball instead on the whole space. The new concepts lead to further investigations and applications. It will be also interesting to apply these concepts in a different metric spaces.

\section{Acknowledgment}

The authors sincerely thank College of Computer Sciences and Information Technology (CCSIT) King Faisal University, Alahssa 31982, Kingdom of Saudi Arabia, to support this research work.

\section{References}

[1] M. Abbas, B. Ali, S. Romaguera, Fixed and periodic points of generalized contractions in metric spaces, Fixed Point Theory Appl., 2013 (2013), 11 pages. 1

[2] M. Abbas, T. Nazir, T. A. Lampert, S. Radenović, Common fixed points of set-valued F-contraction mappings on domain of sets endowed with directed graph, Comp. Appl. Math., 2016 (2016), 16 pages. 1

[3] T. Abdeljawad, Meir-Keeler $\alpha$-contractive fixed and common fixed point theorems, Fixed PoinTheory Appl., 2013 (2013), 10 pages. 1 
[4] Ö. Acar, I. Altun, A fixed point theorem for multivalued mappings with $\delta$-distance, Abstr. Appl. Anal., 2014 (2014), 5 pages. 1

[5] Ö. Acar, G. Durmaz, G. Minak, Generalized multivalued F-contractions on complete metric spaces, Bull. Iranian Math. Soc., 40 (2014), 1469-1478. 1, 1.13, 1.14

[6] H. H. Alsulami, E. Karapınar, H. Piri, Fixed points of generalized F-Suzuki type contraction in complete b-metric spaces, Discrete Dyn. Nat. Soc., 2015 (2015), 8 pages. 1

[7] M. Arshad, E. Ameer, A. Hussain, Hardy-Rogers-type fixed point theorems for $\alpha$-GF-contractions, Arch. Math. (Brno), 51 (2015), 129-141. 1

[8] M. Arshad, Fahimuddin, A. Shoaib, A. Hussain, Fixed point results for $\alpha-\psi$-locally graphic contraction in dislocated qusai metric spaces, [[Corrected title: Fixed point results for $\alpha-\psi$-locally graphic contraction in dislocated quasi metric spaces]] Math. Sci. (Springer), 8 (2014), 79-85. 1

[9] M. Arshad, A. Shoaib, I. Beg, Fixed point of a pair of contractive dominated mappings on a closed ball in an ordered dislocated metric space, Fixed Point Theory Appl., 2013 (2013), 15 pages. 1

[10] M. Arshad, A. Shoaib, P. Vetro, Common fixed points of a pair of Hardy Rogers type mappings on a closed ball in ordered dislocated metric spaces, J. Funct. Spaces Appl., 2013 (2013), 9 pages.

[11] A. Azam, S. Hussain, M. Arshad, Common fixed points of Chatterjea type fuzzy mappings on closed balls, Neural Comput. Appl., 21 (2012), 313-317.

[12] A. Azam, M. Waseem, M. Rashid, Fixed point theorems for fuzzy contractive mappings in quasi-pseudo-metric spaces, Fixed Point Theory Appl., 2013 (2013), 14 pages. 1

[13] S. Banach, Sur les opérations dans les ensembles abstraits et leur application aux équations intégrales, Fund. Math., 3 (1922), 133-181. 1

[14] L. B. Ćirić, A generalization of Banach's contraction principle, Proc. Amer. Math. Soc., 45 (1974), $267-273$.

[15] M. Cosentino, P. Vetro, Fixed point results for F-contractive mappings of Hardy-Rogers-type, Filomat, 28 (2014), 715 722.

[16] M. Edelstein, On fixed and periodic points under contractive mappings, J. London Math. Soc., 37 (1962), 74-79.

[17] B. Fisher, Set-valued mappings on metric spaces, Fund. Math., 112 (1981), 141-145.

[18] M. A. Geraghty, On contractive mappings, Proc. Amer. Math. Soc., 40 (1973), 604-608.

[19] N. Hussain, S. Al-Mezel, P. Salimi, Fixed points for $\psi$-graphic contractions with application to integral equations, Abstr. Appl. Anal., 2013 (2013), 11 pages. 1

[20] N. Hussain, M. Arshad, M. Abbas, A. Hussain, Generalized dynamic process for generalized (f, L)-almost F-contraction with applications, J. Nonlinear Sci. Appl., 9 (2016), 1702-1715. 1

[21] A. Hussain, M. Arshad, S. U. Khan, $\tau$-Generalization of fixed point results for F-contractions, Bangmod Int. J. Math. Comp. Sci., 1 (2015), 136-146.

[22] A. Hussain, M. Arshad, M. Nazam, Connection of Ćirić type F-contraction involving fixed point on closed ball, Gazi Univ. J. Sci., (Accepted). 1

[23] N. Hussain, M. Arshad, A. Shoaib, Fahimuddin, Common fixed point results for $\alpha$ - $\psi$-contractions on a metric space endowed with graph, J. Inequal. Appl., 2014 (2014), 14 pages. 1

[24] N. Hussain, E. Karapınar, P. Salimi, F. Akbar, $\alpha$-admissible mappings and related fixed point theorems, J. Inequal. Appl., 2013 (2013), 11 pages.

[25] N. Hussain, E. Karapınar, P. Salimi, P. Vetro, Fixed point results for G ${ }^{m}$-Meir-Keeler contractive and G- $(\alpha, \psi)-$ MeirKeeler contractive mappings, Fixed Point Theory Appl., 2013 (2013), 14 pages. 1

[26] N. Hussain, P. Salimi, Suzuki-Wardowski type fixed point theorems for $\alpha$-GF-contractions, Taiwanese J. Math., 18 (2014), 1879-1895. 1.4, 1, 1.12, 3

[27] N. Hussain, P. Salimi, A. Latif, Fixed point results for single and set-valued $\alpha-\eta-\psi$-contractive mappings, Fixed Point Theory Appl., 2013 (2013), 23 pages. 1.4, 1.5, 1

[28] E. Karapınar, M. A. Kutbi, H. Piri, D. O'Regan, Fixed points of conditionally F-contractions in complete metric-like spaces, Fixed Point Theory Appl., 2015 (2015), 14 pages. 1

[29] E. Karapinar, B. Samet, Generalized $\alpha-\psi$ contractive type mappings and related fixed point theorems with applications, Abstr. Appl. Anal., 2012 (2012), 17 pages. 1

[30] E. Kreyszig, Introductory functional analysis with applications, Wiley Classics Library. John Wiley \& Sons, Inc., New York, (1989). 1, 1.16

[31] M. A. Kutbi, M. Arshad, A. Hussain, On modified ( $\alpha-\eta)$-contractive mappings, Abstr. Appl. Anal., 2014 (2014), 7 pages. 1

[32] M. A. Kutbi, M. Arshad, A. Hussain, Fixed point results for Ćirić type $\alpha-\eta$-GF-contractions, J. Comput. Anal. Appl., 21 (2016), 466-481. 1

[33] M. A. Kutbi, W. Sintunavarat, On new fixed point results for $(\alpha, \psi, \xi)$-contractive multi-valued mappings on $\alpha$-complete metric spaces and their consequences, Fixed Point Theory Appl., 2015 (2015), 15 pages. 1, 1.6

[34] G. Minak, A. Halvac1, I. Altun, Ćirić type generalized F-contractions on complete metric spaces and fixed point results, Filomat, 28 (2014), 1143-1151. 1

[35] S. B. Nadler Jr., Multi-valued contraction mappings, Pacific J. Math., 30 (1969), 475-488. 1, 1.1

[36] H. Piri, P. Kumam, Some fixed point theorems concerning F-contraction in complete metric spaces, Fixed Point Theory Appl., 2014 (2014), 11 pages. 1, 1.7, 3 
[37] P. Salimi, A. Latif, N. Hussain, Modified $\alpha-\psi$-contractive mappings with applications, Fixed Point Theory Appl., 2013 (2013), 19 pages. 1.3

[38] B. Samet, C. Vetro, P. Vetro, Fixed point theorems for $\alpha \psi$-contractive type mappings, Nonlinear Anal., 75 (2012), 2154-2165. 1.2

[39] N. A. Secelean, Iterated function systems consisting of F-contractions, Fixed Point Theory Appl., 2013 (2013), 13 pages. 1

[40] M. Sgroi, C. Vetro, Multi-valued F-contractions and the solution of certain functional and integral equations, Filomat, 27 (2013), 1259-1268. 1, 1

[41] A. Shoaib, M. Arshad, J. Ahmad, Fixed point results of locally cotractive mappings in ordered quasi-partial metric spaces, Scientific World J., 2013 (2013), 8 pages. 1

[42] A. Shoaib, A. Hussain, M. Arshad, A. Azam, Fixed point results for $\alpha_{*}-\psi$-Ciric type multivalued mappings on an intersection of a closed ball and a sequence with graph, J. Math. Anal., 7 (2016), 41-50. 1

[43] S. Shukla, S. Radenović, Some common fixed point theorems for F-contraction type mappings on 0-complete partial metric spaces, J. Math., 2013 (2013), 7 pages.

[44] S. Shukla, S. Radenović, Z. Kadelburg, Some fixed point theorems for ordered F-generalized contractions in 0-f-orbitally complete partial metric spaces, Theory Appl. Math. Comput. Sci., 4 (2014), 87-98. 1

[45] D. Wardowski, Fixed points of a new type of contractive mappings in complete metric spaces, Fixed Point Theory Appl., 2012 (2012), 6 pages. 1, 1.8, 1.9, 1, 1.11, 3 